\title{
A Versatile Method for Ammonia Detection in a Range of Relevant Electrolytes via Direct Nuclear Magnetic Resonance Techniques
}

Nielander, Adam C.; McEnaney, Joshua M.; Schwalbe, Jay A.; Baker, Jon G.; Blair, Sarah J.; Wang, Lei; Pelton, Jeffrey G.; Andersen, Suzanne Zamany; Enemark-Rasmussen, Kasper; Colic, Viktor

Total number of authors:

17

Published in:

ACS Catalysis

Link to article, DOI:

10.1021/acscatal.9b00358

Publication date:

2019

Document Version

Early version, also known as pre-print

Link back to DTU Orbit

Citation (APA):

Nielander, A. C., McEnaney, J. M., Schwalbe, J. A., Baker, J. G., Blair, S. J., Wang, L., Pelton, J. G., Andersen, S. Z., Enemark-Rasmussen, K., Colic, V., Yang, S., Bent, S. F., Cargnello, M., Kibsgaard, J., Vesborg, P. C. K., Chorkendorff, I., \& Jaramillo, T. F. (2019). A Versatile Method for Ammonia Detection in a Range of Relevant Electrolytes via Direct Nuclear Magnetic Resonance Techniques. ACS Catalysis, 9(7), 5797-5802. https://doi.org/10.1021/acscatal.9b00358

\section{General rights}

Copyright and moral rights for the publications made accessible in the public portal are retained by the authors and/or other copyright owners and it is a condition of accessing publications that users recognise and abide by the legal requirements associated with these rights.

- Users may download and print one copy of any publication from the public portal for the purpose of private study or research.

- You may not further distribute the material or use it for any profit-making activity or commercial gain

- You may freely distribute the URL identifying the publication in the public portal 


\section{Supporting Information}

\section{A Versatile Method for Ammonia Detection in a Range of Relevant Electrolytes via Direct Nuclear Magnetic Resonance Techniques}

Author List: Adam C. Nielander ${ }^{\dagger}$, Joshua M. McEnaney ${ }^{\dagger}$, Jay A. Schwalbe ${ }^{\dagger}$, Jon G. Baker ${ }^{\dagger}$, Sarah J. Blair $^{\dagger}$, Lei Wang ${ }^{\dagger}$, Jeffrey G. Pelton ${ }^{\star}$, Suzanne Z. Andersen ${ }^{\S}$, Kasper Enemark-Rasmussen ${ }^{\nabla}$, Viktor Čolić ${ }^{\S}$, Sungeun Yang ${ }^{\S}$, Stacey F. Bent ${ }^{\dagger}$, Matteo Cargnello ${ }^{\dagger}$, Jakob Kibsgaard ${ }^{\S}$, Peter C. K. Vesborg $\$$, Ib Chorkendorff ${ }^{\S}$, Thomas F. Jaramillo*,†

†Department of Chemical Engineering, Stanford University

443 Via Ortega, Stanford, California 94305, United States

QB3 Institute, University of California, Berkeley, California, 94720

${ }^{\S}$ Department of Physics, Technical University of Denmark, Building 311, Fysikvej, DK-2800 Kgs. Lyngby, Denmark

$\nabla$ Department of Chemistry, Technical University of Denmark, Building 207, DK-2800 Kgs. Lyngby, Denmark

*Corresponding Author; E-mail: jaramillo@stanford.edu 


\section{Table of Contents}

1. Experimental Methods $\quad$ S3

2. 1D NOESY Suppression Method S6

3. Pulse sequence diagram $\quad$ S8

4. Various pulse sequences NMR spectra $\quad S 9$

5. $1 \mu \mathrm{M} \mathrm{NH}_{4}{ }^{+}$in EtOH, $1 \mathrm{hr}$ acquisition, NMR detection, $900 \mathrm{MHz} \mathrm{NMR} \quad \mathrm{S} 10$

6. $10 \mu \mathrm{M} \mathrm{NH}_{4}{ }^{+}$in $\mathrm{EtOH}, 20$ min acquisition, NMR detection, $600 \mathrm{MHz}$ NMR S11

7. Frequency-selective PGSE pulse sequence solvent compatibility $\quad$ S12

8. Calibration curve for $\mathrm{NH}_{4}{ }^{+}$in $\mathrm{H}_{2} \mathrm{O} \quad \mathrm{S} 13$

9. Shaped Pulse Frequency Dependence $\quad$ S14

10. Effect of paramagnetic ion on $\mathrm{NH}_{4}{ }^{+}$signal $\quad \mathrm{S} 15$

11. $\mathrm{H}_{2} \mathrm{SO}_{4}$ concentration/' $\mathrm{pH}$ ' dependence $\quad \mathrm{S} 16$

12. $\mathrm{NH}_{4}{ }^{+}$resonance peak shape dependence on locking solvent $\quad \mathrm{S} 17$

13. Colorimetric (Berthelot) $\mathrm{NH}_{3}$ detection characterization $\quad \mathrm{S} 18$

14. SI References $\quad$ S24 


\section{1) Experimental Methods}

Materials

Ammonium chloride (Fisher, ACS Grade) and lithium triflate [LiOTf] (Sigma-Aldrich, 99.995\%) were used as received. Ethanol (Fisher Scientific, Absolute, ACS Grade) , tetrahydrofuran [THF] (Sigma-Aldrich, anhydrous, inhibitor-free, 99.9\%), diethyl ether (Fisher Scientific, anhydrous, ACS grade), hexane (Sigma-Aldrich, mixture of isomers, 98.5\%), acetonitrile (Sigma-Aldrich, anhydrous, 99.8\%), dimethylsulfoxide [DMSO] (Fisher Scientific, anhydrous, ACS grade), and propylene carbonate (Sigma-Aldrich, anhydrous, 99.8\%) were used as received. Copper (II) sulfate pentahydrate (Fisher Scientific, 98\%) and Ethylenediaminetetraacetic acid, disodium salt [EDTA] (Invitrogen, 99\%, 'Ultrapure') were used as received. Water was obtained from a Millipore system $(18.2 \mathrm{M} \Omega \mathrm{cm}) .5 \mathrm{~mm}$ NMR tubes were used in all NMR experiments (Norell, Standard Series). $1 \mathrm{~cm}$ optical glass cuvettes (Starna Cells Inc., Atascadero, CA) were used in UV-Vis/colorimetric experiments. Sodium salicylate (SigmaAldrich, 99\%), sodium nitroprusside (Sigma-Aldrich, 99\%), sodium hydroxide (Sigma-Aldrich, 99.9\%) and sodium hypochlorite (Sigma-Aldrich, 4-4.99\% aqueous solution) were used as received. Final concentrations of sodium hypochlorite after dilution were calculated assuming $5 \%$ mass/mass initial concentration. Analytes for both the NMR and colorimetric method were prepared in the reported concentrations by the dissolution of $\mathrm{NH}_{4} \mathrm{Cl}$ and/or LiOTf into the appropriate solvent. Some solvents (e.g. hexanes, diethyl ether, propylene carbonate) required the addition of a co-solvent (ethanol and/or water) in order to fully dissolve $\mathrm{NH}_{4} \mathrm{Cl}$ and/or LiOTf.

\section{NMR Method (Frequency-Selective Pulsed Gradient Spin Echo)}

NMR samples were prepared by the addition of $500 \mu \mathrm{L}$ analyte to an Eppendorf tube, followed by the successive addition of locking solvent (DMSO- $d_{6}$, unless otherwise noted), calibration standard (where needed), and acid ( $0.1 \mathrm{M} \mathrm{H}_{2} \mathrm{SO}_{4}$ unless otherwise noted). Care was taken to ensure complete mixing prior to the addition of the mixture to the NMR tube, which was necessary to observe sharp $\mathrm{NH}_{4}{ }^{+}$resonances.

NMR spectra were recorded on an Avance II Bruker NMR spectrometer operating at 900 $\mathrm{MHz}$ and at $25{ }^{\circ} \mathrm{C}$ except where noted. The instrument was equipped with a $\mathrm{TCl}$ cryoprobe and 16-sample sample changer. A frequency-selective pulse gradient spin echo sequence (See Figure S2) consisting of a hard $90^{\circ}$ pulse followed by a gradient - selective $180^{\circ}$ - gradient echo pulse sequence was employed except where noted. ${ }^{1}$ This sequence is implemented in Bruker Topspin 3.2 as 'selgpse'. In a typical experiment $128 \mathrm{k}$ complex points were recorded for each spectrum with the carrier frequency set to the hydroxyl resonance of ethanol (approximately $4.82 \mathrm{ppm}$ ) and the spectral width set to $16 \mathrm{ppm}$. The recycle and acquisition delays were $1.5 \mathrm{sec}$ and $2.27 \mathrm{sec}$, respectively, for a total relaxation delay of $3.77 \mathrm{sec}$. The number of scans ranged from 16 for samples with ammonia at $100 \mu \mathrm{M}$ concentrations to 1024 scans for samples with ammonia at near or sub-micromolar concentrations. The gradient pulses were applied as the positive half of a sine wave form defined by 100 points for 1 millisecond at a strength of 2.5 Gauss/cm. The 180 degree shaped pulse was applied as a Gaussian wave form (Bruker shape file Gaus1_180r.1000) defined by one thousand points for 1500 microseconds. The shaped 
pulse was located near the ammonia and reference standard signals by shifting it $2.67 \mathrm{ppm}$ downfield from the carrier frequency. Because of the non-uniform excitation profile, it was important to maintain the same carrier frequency between spectra compared quantitatively. The phase of hard $90^{\circ}$ pulse and shaped $180^{\circ}$ pulses were $\{x x y y-x-x-y-y\}$ and $\{y,-y\}$, respectively and the phase of the receiver was $\{x x-y-y x x y y\}$.

The data were processed using either Topspin (version 3.2, Bruker Biospin Inc, Billerica, MA. USA) or MNova (version 12, Mestrenova Research S. L., Escondido, CA. USA) by baseline correction of the fid, line broadening $(1 \mathrm{~Hz})$, Fourier transformation, and phasing. In some cases, baseline distortions were observed. The distortions were corrected by converting the data from digital to analog form, re-creating the first twelve to thirty-two points by back linear prediction, and processing as described. Prior to integration, the baseline in the region that contained the signals of interest $(8-6.8 \mathrm{ppm})$ was adjusted to zero using algorithms supplied within the processing programs. Chemical shifts were referenced to tetramethylsilane (TMS) in non-aqueous solvents and trimethylsilylpropionic acid (TSP) in water. For each sample, the concentration of the ammonium ion was determined by calculating the ratio of the area under the ammonium peak and that of the standards (a synthetic standard generated using the ERETIC2 routine; or chloroform, 1,3,5-trimethoxybenzene, or hydroquinone) and comparison to a standard curve. ERETIC refers to 'Electronic REference To access In vivo Concentrations', a method developed to generate a repeatable, synthetic, NMR signal for the purpose of calibration of analyte concentration. ${ }^{2,3} \mathrm{~A}$ version of this method, ERETIC2, implemented in Topspin 3.2 based on the PULCON method, was used herein. ${ }^{4}$ We note that the MNova qNMR package was also capable of efficiently quantifying $\mathrm{NH}_{3}$ concentrations using a synthetic signal. Because the relaxation delay of $3.77 \mathrm{sec}$ is less than the time needed for full recovery of the magnetization of the standards (usually 5 T1s), it was important to develop and compare the actual data to a standard curve developed under similar experimental conditions when using internal chemical standards. The effective measured $\mathrm{T} 1$ time of the $\mathrm{NH}_{4}^{+}$resonance in $\mathrm{EtOH}$ was found to be $183 \mathrm{~ms}$. Effective T1 time is reported because the measured T1 may be due to exchange with solvent. Use of the ERETIC2 standard was found to be advantageous because it did not require consideration of chemical calibration standard $\mathrm{T} 1$ time (measured $\mathrm{CHCl}_{3}$ $\mathrm{T} 1=5.72 \mathrm{~s}$ in $40 \mu \mathrm{M} \mathrm{CHCl}_{3}$ in EtOH solution), particularly in light of the short $\mathrm{NH}_{4}{ }^{+} \mathrm{T} 1$ time, and is recommended where possible.

Electrochemical measurements (Figure 3c) were performed using an SP-300 potentiostat (Bio-Logic Science Instruments SAS) according to a previously reported method. ${ }^{5}$ Lithium triflate was used as a supporting electrolyte in lieu of lithium perchlorate as reported in reference 5 .

\section{NMR Method (Frequency-Selective Pulsed Gradient Spin Echo) (Tutorial Description)}

The frequency-selective PGSE NMR method described herein can be readily applied via a simple chemical manipulation described below. After attempting $\mathrm{N}_{2}$ electroreduction in an electrolyte, take a $500 \mu \mathrm{L}$ aliquot of the electrolyte and add it to a clean glass container. Add $25 \mu \mathrm{L}$ DMSO$\mathrm{d}_{6}$ to the electrolyte followed by $50 \mu \mathrm{L}$ of an aqueous $0.5 \mathrm{M} \mathrm{H}_{2} \mathrm{SO}_{4}$ solution. If the electrolyte solvent is immiscible with $\mathrm{H}_{2} \mathrm{O}$, an additional small volume of ethanol can be added to promote miscibility. The addition of $\mathrm{H}_{2} \mathrm{SO}_{4}$ may also drive precipitation of the supporting electrolyte. 
Avoiding precipitate transfer to the NMR tube is advantageous but not critical. Transfer the prepared electrolyte to an NMR tube. The recommended pulse sequence and selective $180^{\circ}$ pulse shape are readily available in the Bruker TopSpin software ('selgspe' and 'Gaus1_180r.1000' respectively), but should be available on most modern NMR instruments. No internal chemical standard is required as both Bruker TopSpin and the and MNova 12 software have routines capable of determining an unknown analyte concentration after defining a reference spectrum with a known analyte concentration.

\section{Colorimetric Method}

UV-Visible spectra were taken using a Cary 300 BIO instrument. Spectra were obtained between $800 \mathrm{~nm}$ and $400 \mathrm{~nm}$ with a scan rate of $300 \mathrm{~nm} / \mathrm{min}$. Analytes were prepared variously by dilution of the electrolytes by volume with pure ethanol or water to a total volume of $2 \mathrm{~mL}$ in order to promote homogenous mixing of all solution components and color development (see Table S1, 'Solvent Conditions'). For example, a propylene carbonate-based standard analyte (e.g. $10 \mu \mathrm{M} \mathrm{NH}{ }_{4} \mathrm{Cl}+0.1 \mathrm{M} \mathrm{LiOTf}$ in propylene carbonate solution) was prepared by the addition of $1 \mathrm{~mL}$ propylene carbonate analyte to $0.5 \mathrm{~mL}$ water and $0.5 \mathrm{~mL} \mathrm{EtOH}(50 \%$ electrolyte, $25 \% \mathrm{EtOH}, 25 \% \mathrm{H}_{2} \mathrm{O}$ ). The necessary solution volumes of each reactant were added to a $2 \mathrm{~mL}$ analyte sample volume in order to achieve the reactant concentrations reported in Table S1. Suggested concentrations of reactant solutions are as follows: sodium salicylate (2.5 $\mathrm{M})$, sodium hydroxide $(1.0 \mathrm{M})$, sodium nitroprusside $(0.2 \mathrm{M})$, sodium hypochlorite $(5 \%$ mass/mass in solution). Samples were collected in cuvettes made of optical glass to minimize incompatibilities with polymer-based, disposable cuvettes. Absorbances were reported at the $\lambda_{\max }$ (between 660nm-670nm) associated with the dicarboxylated indophenol product. Absorbance values were corrected with respect to a background spectrum composed of identical electrolyte and reaction conditions, but no measurable $\mathrm{NH}_{3}$. 


\section{2) 1D NOESY Suppression Method}

Although the frequency-selective pulsed gradient spin echo method offers unparalleled ease-of-use and versatility, the acquired spectra only identifies a small part of the compounds present in the sample. From a quantification point-of-view, this may be sufficient, but nevertheless suppressing only the solvent peaks offers more information about the sample composition, which can potentially be useful for studies into degradation and reaction processes taking place during the synthesis of $\mathrm{NH}_{3}$. For suppression of three solvent peaks (e.g. ethanol) the 1D NOESY pulse sequence needed minor modifications as severe baseline distortions is introduced when saturating three signals with one shaped pulse. Using a twochannel systems we found that the best option was to discard ${ }^{13} \mathrm{C}$ decoupling and applying a double-selective shaped pulse (around $50 \mathrm{~ms}$ ) on one channel saturating both the $\mathrm{CH}_{2}$ (onresonance) and $\mathrm{CH}_{3}$ (off-resonance) multiplets, while the other channel employs a standard cwpresaturation at the $\mathrm{OH}$ resonance. For a three-channel system the ${ }^{13} \mathrm{C}$ decoupling is included and offers a small but significant improvement in the overall solvent suppression. With this method, reduced signal-to-noise as compared to the frequency-selective gradient spin echo method in the same duration were observed (approx. 20\% S/N improvement for frequencyselective PGSE compared to suppression), but minor signals originating from secondary compounds in the sample were still observed. Only minor J-modulation is introduced during the saturation pulse and reliable integrals can be extracted for both $\mathrm{NH}_{4}{ }^{+}$and an added internal standard. Thus, a quantitative analysis is still possible. The pulse sequence can be used both manually and in automation, although it ultimately requires (considerably) more setup time as compared to the frequency-selective PGSE method.

Spectra obtained using the NOESY method were collected on a Bruker Avance III spectrometer operating at a ${ }^{1} \mathrm{H}$ frequency of $600.165 \mathrm{MHz}$ equipped with a Bruker broadband Smart Probe (BBFO) to compare the frequency-selective pulsed gradient spin echo and the 1D NOESY suppression techniques (Figure S1) reported previously. ${ }^{6}$ In this comparison, the frequency-selective PGSE used the following parameters: $n s=256, d 1=0.8 \mathrm{~s}, \mathrm{AQ}=1.36, T D=32 \mathrm{~K}$, $\mathrm{p} 12$ (refocus) $=1500 \mu$ s centered at $7.46 \mathrm{ppm}, \mathrm{o} 1 \mathrm{p}=5.242 \mathrm{ppm}$. The 1D NOESY suppression technique used the following parameters: $n s=256, d 1=0.8 \mathrm{~s}, \mathrm{AQ}=1.36 \mathrm{~s}, \mathrm{TD}=32 \mathrm{~K}$. In THF, p23 was set to affect both THF-signals (3.56 ppm and $1.71 \mathrm{ppm})$, while also applying $\mathrm{cw}$ presaturation (using F2) at $1.71 \mathrm{ppm} .01 \mathrm{p}=3.56 \mathrm{ppm}$. 


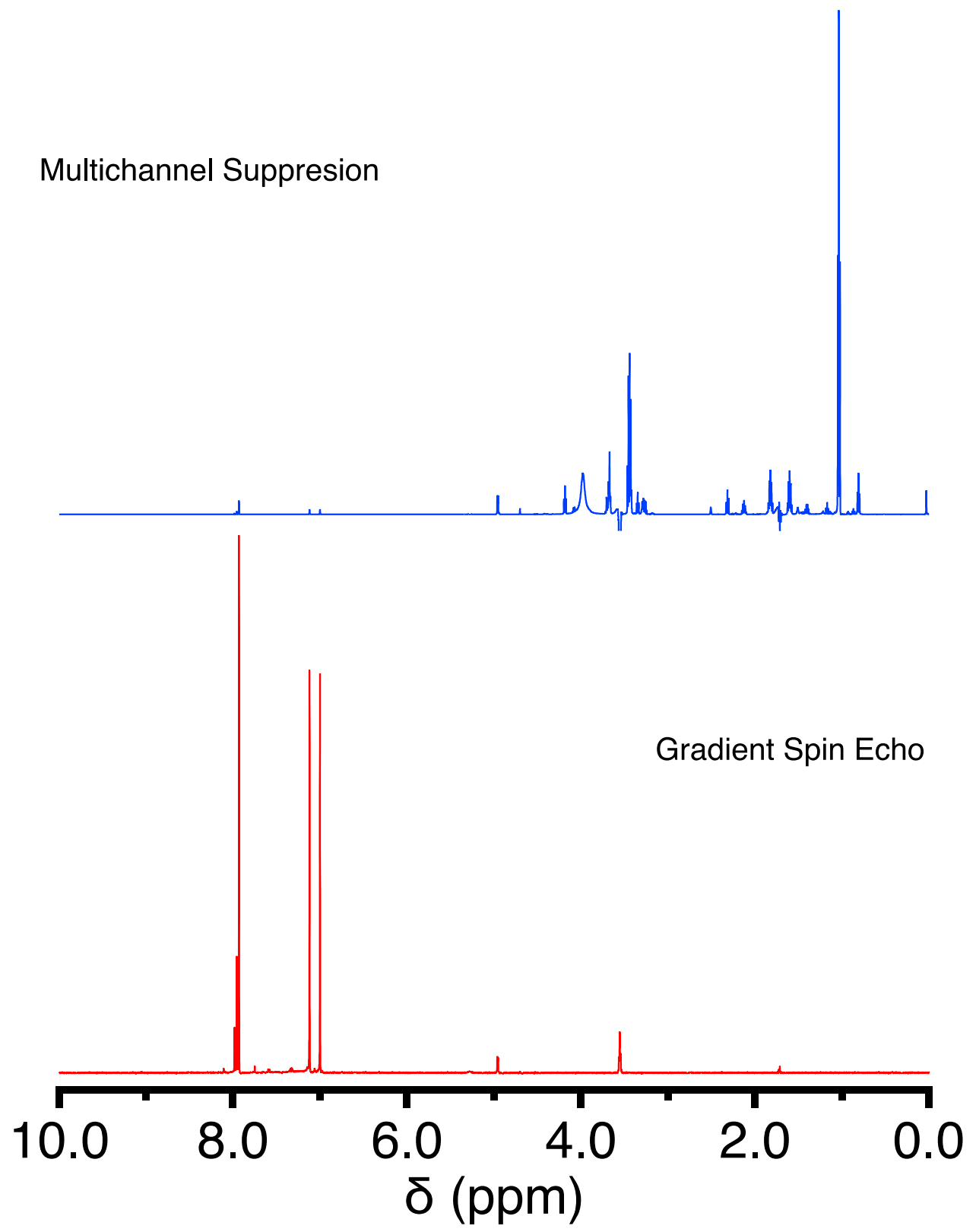

Figure S1. NMR spectrum of a $0.1 \mathrm{M} \mathrm{LiClO}_{4}$ in $1 \% \mathrm{EtOH} / \mathrm{THF}$ electrolyte after executing previously reported electrochemical $\mathrm{N}_{2}$ reduction technique using ${ }^{15} \mathrm{~N}_{2} \cdot{ }^{5}$ (blue) NMR spectrum obtained using 1D NOESY suppression technique $\left(\mathrm{NH}_{4}{ }^{+} \mathrm{S} / \mathrm{N}\right.$ Ratio: 432$)$. (red) NMR spectrum obtained using a frequency-selective pulsed gradient spin-echo pulse sequence $\left(\mathrm{NH}_{4}{ }^{+} \mathrm{S} / \mathrm{N}\right.$ Ratio: 561). 


\section{3) Pulse sequence diagram}

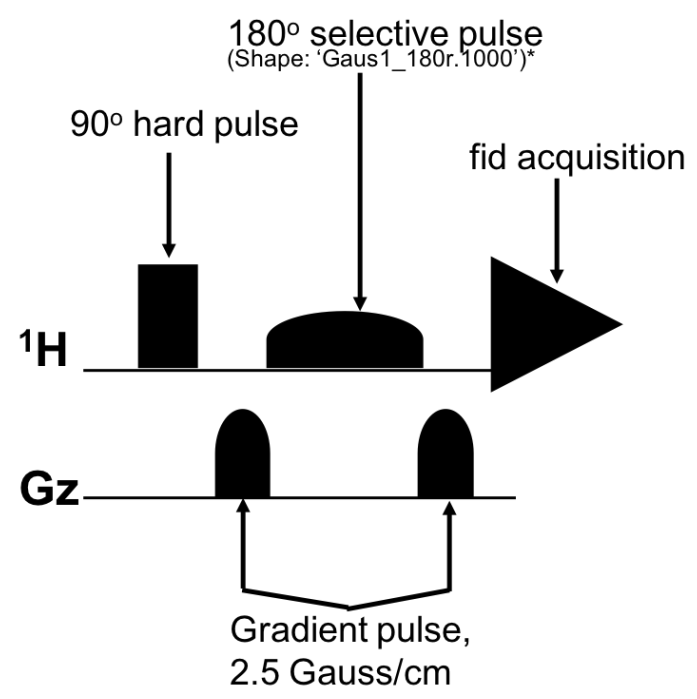

Figure S2. Frequency-selective PGSE sequence used to selectively observe $\mathrm{NH}_{4}{ }^{+}$resonance in non-deuterated electrolytic solutions. A hard $90^{\circ}$ pulse followed by a gradient - selective $180^{\circ}$ pulse - gradient echo pulse sequence was employed. ${ }^{1} \mathrm{H}$ refers to the observed channel and $\mathrm{G}_{\mathrm{x}}$ refers to the gradient channel. * Selective $180^{\circ}$ pulse shape defined as a Gaussian wave form using Bruker shape 'Gaus1_180r.1000'. The phase of hard $90^{\circ}$ pulse and shaped $180^{\circ}$ pulses were $\{x x y y-x-x-y-y\}$ and $\{y,-y\}$, respectively and the phase of the receiver was $\{x x-y-y x x$ y y $\}$. 


\section{4) Various pulse sequences NMR spectra}

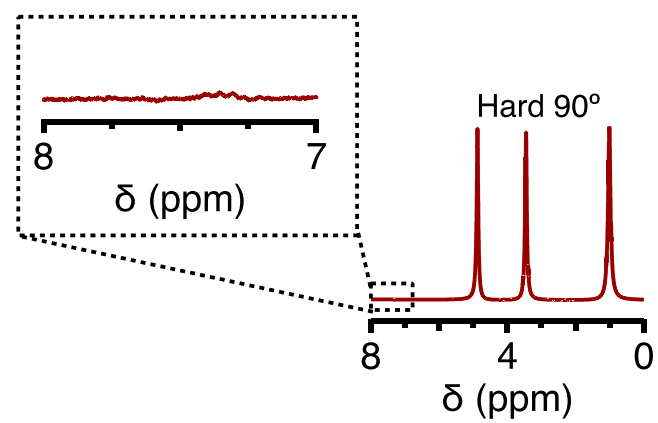

(A)

(D)
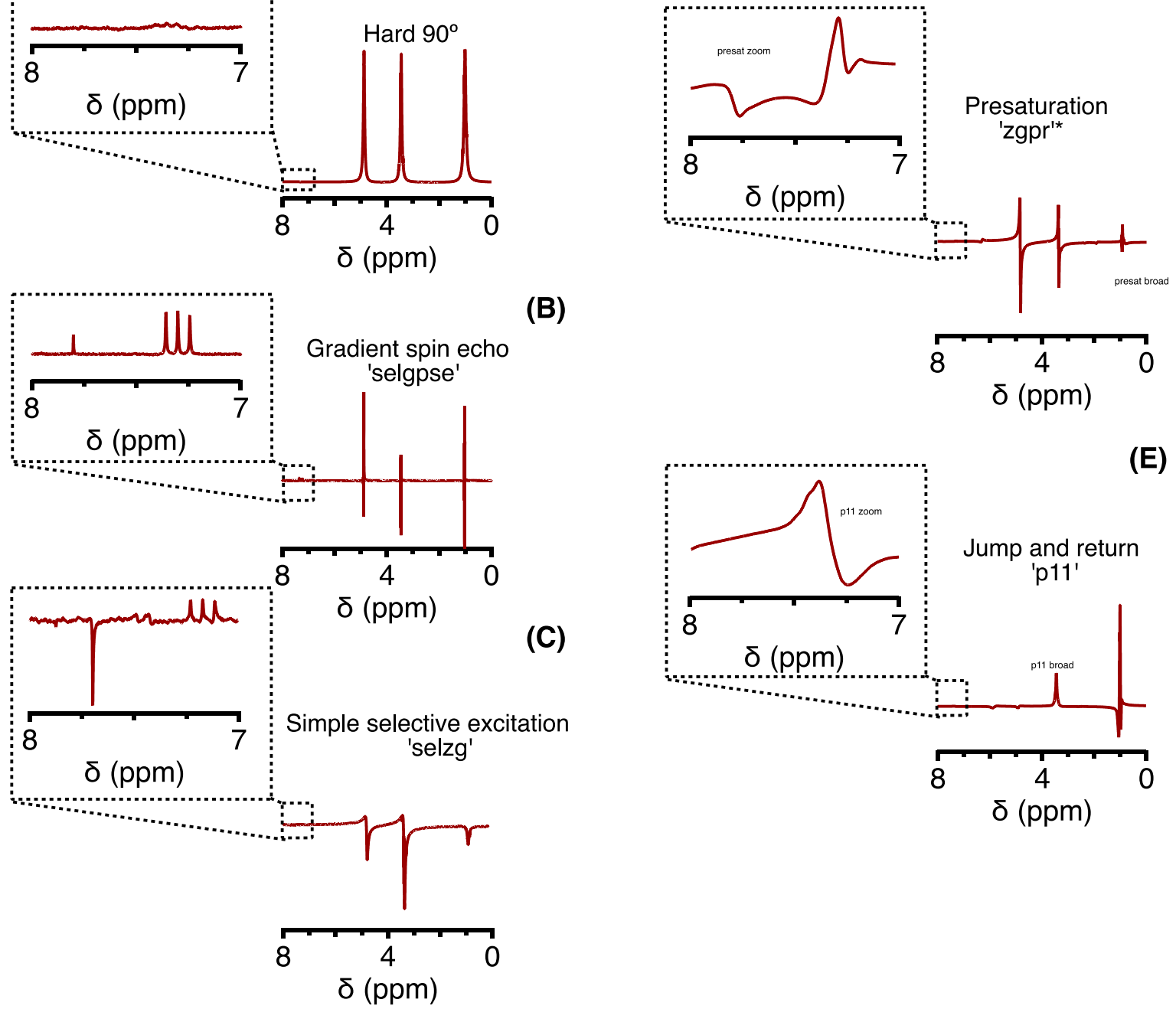

(B)

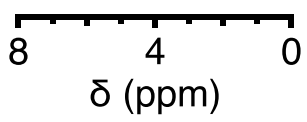

(E)

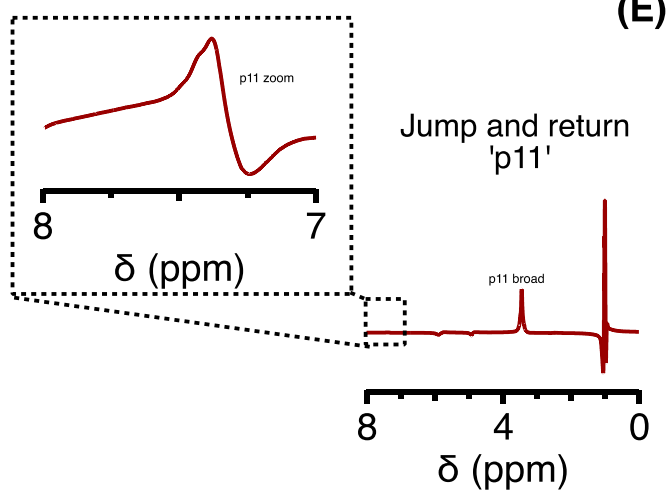

Figure S3. NMR spectrum of $100 \mu \mathrm{M} \mathrm{NH}_{4}{ }^{+} / 0.1 \mathrm{M}$ LiOTf in EtOH using various pulse sequences. The entry for each pulse sequence in the Bruker Pulse Program Catalogue is listed in parentheses. A) Standard hard $90^{\circ}$ pulse. $\mathrm{No}^{\mathrm{NH}_{4}}{ }^{+}$resonance observed. B) Frequency-selective PGSE. $\mathrm{NH}_{4}{ }^{+}$resonance and chemical standard resonance readily observed. C) Simple selective excitation pulse. $\mathrm{NH}_{4}{ }^{+}$resonance observed, but phase information degraded and demonstrated by inverted chemical standard reference at $7.7 \mathrm{ppm}$. D) Presaturation pulse. $\mathrm{No} \mathrm{NH}_{4}{ }^{+}$resonance observed, artifacts present in region of $\mathrm{NH}_{4}{ }^{+}$chemical shift. ${ }^{*}$ Note that a presaturation pulse was applied to each of the three EtOH resonance peaks in turn while using this pulse sequence instead of the multichannel 1D NOESY suppression demonstrated in previously reported work. E) Jump and return pulse. $\mathrm{No} \mathrm{NH}_{4}{ }^{+}$resonance observed, artifacts present in region of $\mathrm{NH}_{4}{ }^{+}$ chemical shift. 


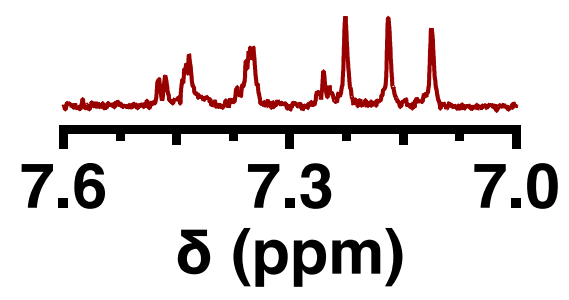

Figure S4. NMR spectrum of $1 \mu \mathrm{M} \mathrm{NH}_{4}{ }^{+}$in EtOH detected using a $900 \mathrm{MHz} \mathrm{NMR}$ instrument equipped with a cryocooled probe. Total spectrum acquisition time was 59 minutes and 59 seconds. Acquisition time and recycle delay (D1) were each reduced to $\sim 1$ second in order to maximize the rate of data collection. Peaks seen to the left of the $\mathrm{NH}_{4}{ }^{+}$resonance were assigned as impurities and were consistently present in spectra in which $1 \mu \mathrm{M} \mathrm{NH}_{4}{ }^{+}$was resolved. 
6) $10 \mu \mathrm{M} \mathrm{NH}{ }_{4}{ }^{+}$in EtOH, 25 min acquisition, NMR detection, $600 \mathrm{MHz}$ NMR

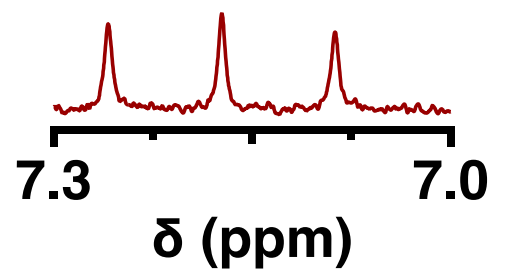

Figure S5. NMR spectrum of $10 \mu \mathrm{M} \mathrm{NH}_{4}{ }^{+}$in EtOH detected using a $600 \mathrm{MHz}$ Varian INOVA NMR instrument equipped with a room temperature probe $(5 \mathrm{~mm} \mathrm{HCN})$ using frequency-selective PGSE. NMR parameters were as follows: $T D=64 K, A Q=2.0 \mathrm{~s}, \mathrm{~ns}=128$, gain $=40, \mathrm{~d} 1=1 \mathrm{~s}, \mathrm{pw}=8.3 \mu \mathrm{s}$, transmitter offset from EtOH OH resonance: $2.43 \mathrm{ppm}$. Total spectrum acquisition time was $\sim 25$ minutes. 
7) Frequency-selective PGSE pulse sequence solvent compatibility
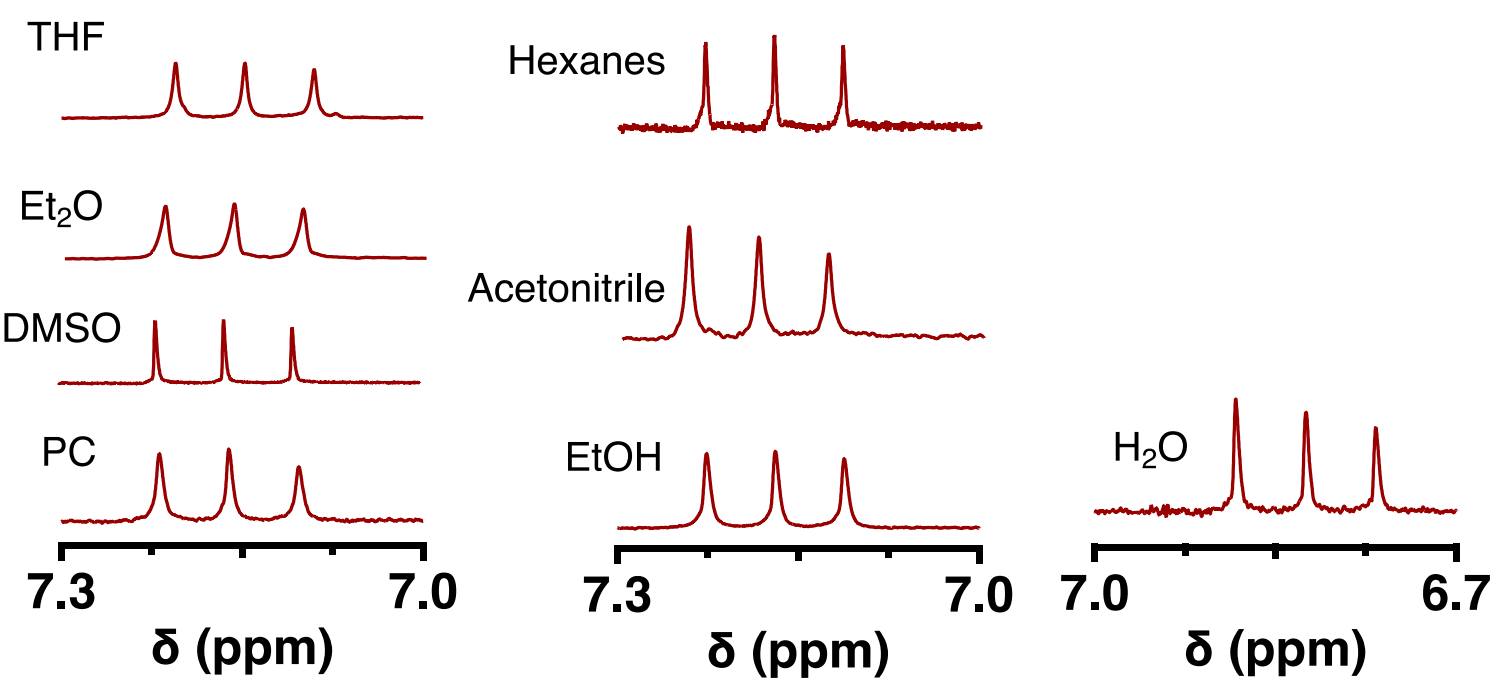

Figure S6. NMR spectra of $100 \mu \mathrm{M} \mathrm{NH}_{4}{ }^{+}$in $\mathrm{THF}, \mathrm{Et}_{2} \mathrm{O}$, DMSO, Propylene carbonate, hexanes, acetonitrile, ethanol, and water. 


\section{8) Calibration curve for $\mathrm{NH}_{4}{ }^{+}$in $\mathrm{H}_{2} \mathrm{O}$}

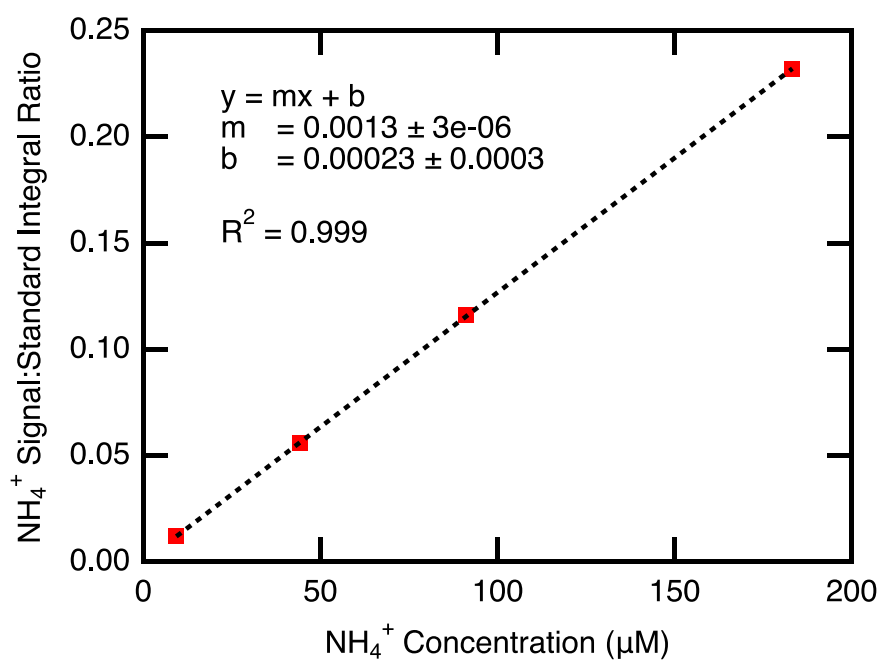

Figure S7: Calibration curve generated via NMR for the determination of $\mathrm{NH}_{4}{ }^{+}$concentration in water. Measurements of the ratio of a $\mathrm{NH}_{4}{ }^{+}$:standard integral were taken in triplicate at 183, 91,44 , and $9 \mu \mathrm{M}$ concentrations. The dotted black line represents the fitted curve. The standard deviation for each triplicate measurement was less than or equal to $3 \%$ of the mean value observed. The standard was generated synthetically using the ERETIC2/PULCON method. Note that the slope of the calibration line depends on the concentration of the chosen $\mathrm{NH}_{4}{ }^{+}$ standard. 


\section{9) Shaped Pulse Frequency Dependence}

(A)

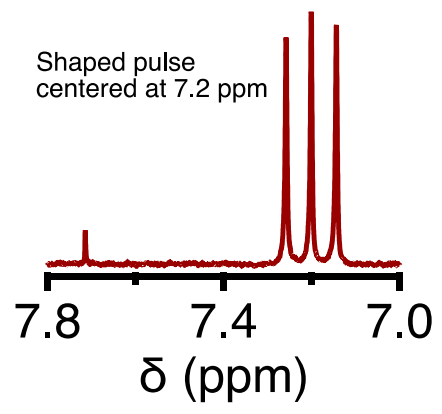

(B)

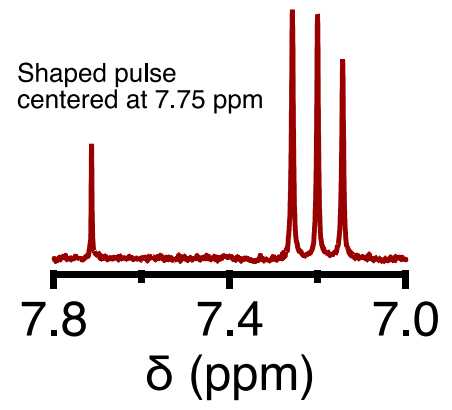

(C)

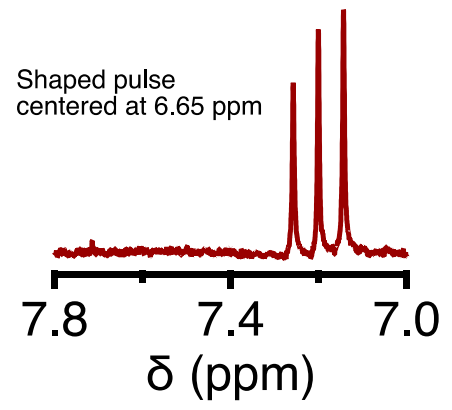

Figure S8. NMR spectrum of $100 \mu \mathrm{M} \mathrm{NH}_{4}{ }^{+}$and $\sim 50 \mu \mathrm{M} \mathrm{CHCl}_{3}$ in EtOH detected using various shaped pulse center frequency parameters in the frequency-selective pulsed gradient spin echo pulse sequence routine. 


\section{0) Effect of paramagnetic ion on $\mathrm{NH}_{4}{ }^{+}$signal}

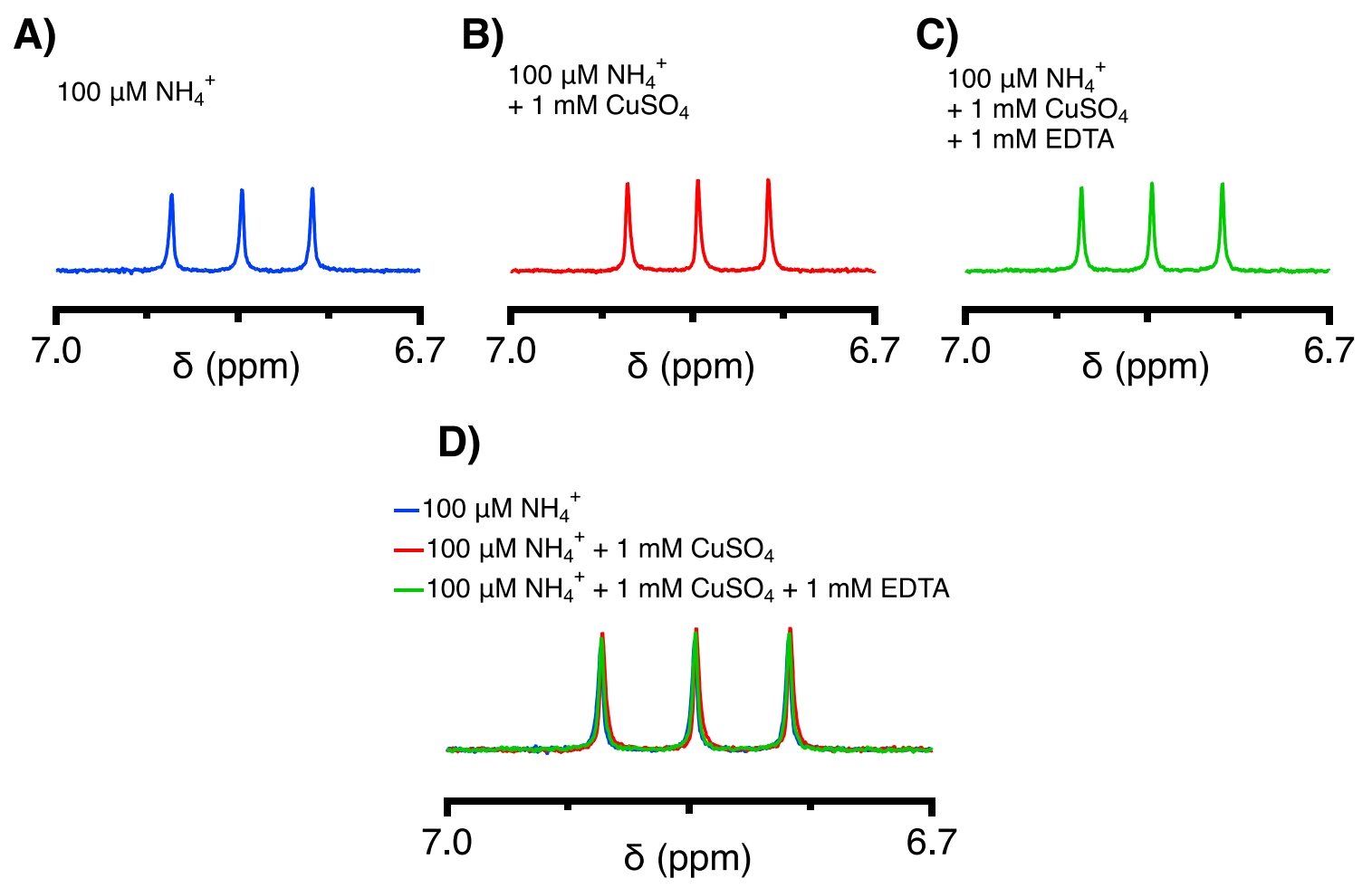

Figure S9: NMR spectra of analytes composed of A) $100 \mu \mathrm{M} \mathrm{NH}_{4}{ }^{+}$in $\mathrm{H}_{2} \mathrm{O}$, B) $100 \mu \mathrm{M} \mathrm{NH}_{4}{ }^{+}$and 1 $\mathrm{mM} \mathrm{CuSO}_{4}$ in $\left.\mathrm{H}_{2} \mathrm{O}, \mathrm{C}\right) 100 \mu \mathrm{M} \mathrm{NH}_{4}{ }^{+}, 1 \mathrm{mM} \mathrm{CuSO}_{4}$, and $1 \mathrm{mM} \mathrm{EDTA}$ in $\mathrm{H}_{2} \mathrm{O}$. Panel D) is each of the spectra in panels $A), B$ ), and C) overlaid.

In order to determine the effect of paramagnetic species on the quality of the $\mathrm{NH}_{4}{ }^{+}$signal using the frequency-selective PGSE NMR method, we added a $\mathrm{Cu}$ (II) species (1 $\mathrm{mM} \mathrm{CuSO}_{4}$ ) to a solution containing $100 \mu \mathrm{M} \mathrm{NH}_{4}{ }^{+}$in $\mathrm{H}_{2} \mathrm{O}$. We observed no significant difference in the spectra between these two analytes upon addition of $\mathrm{CuSO}_{4}$ (Figure S9a and $\mathrm{S9b}$ ). We additionally collected the NMR spectrum of an analyte containing $100 \mu \mathrm{M} \mathrm{NH}_{4}{ }^{+}, 1 \mathrm{mM} \mathrm{CuSO}_{4}$, and $1 \mathrm{mM}$ EDTA. EDTA can be used to sequester paramagnetic species in solution to improve NMR spectra, and while EDTA was ultimately not needed to improve the $\mathrm{NH}_{4}{ }^{+}$signal in Figure S9, it may be valuable for other paramagnetic impurities and did not reduce the spectrum quality (Figure S9c). If paramagnetic species are a significant concern for an analyte, we suggest adding a small amount of $\mathrm{NH}_{4}{ }^{+}$to the analyte to confirm that the $\mathrm{NH}_{4}{ }^{+}$signal can be observed in the presence of the paramagnetic species. 


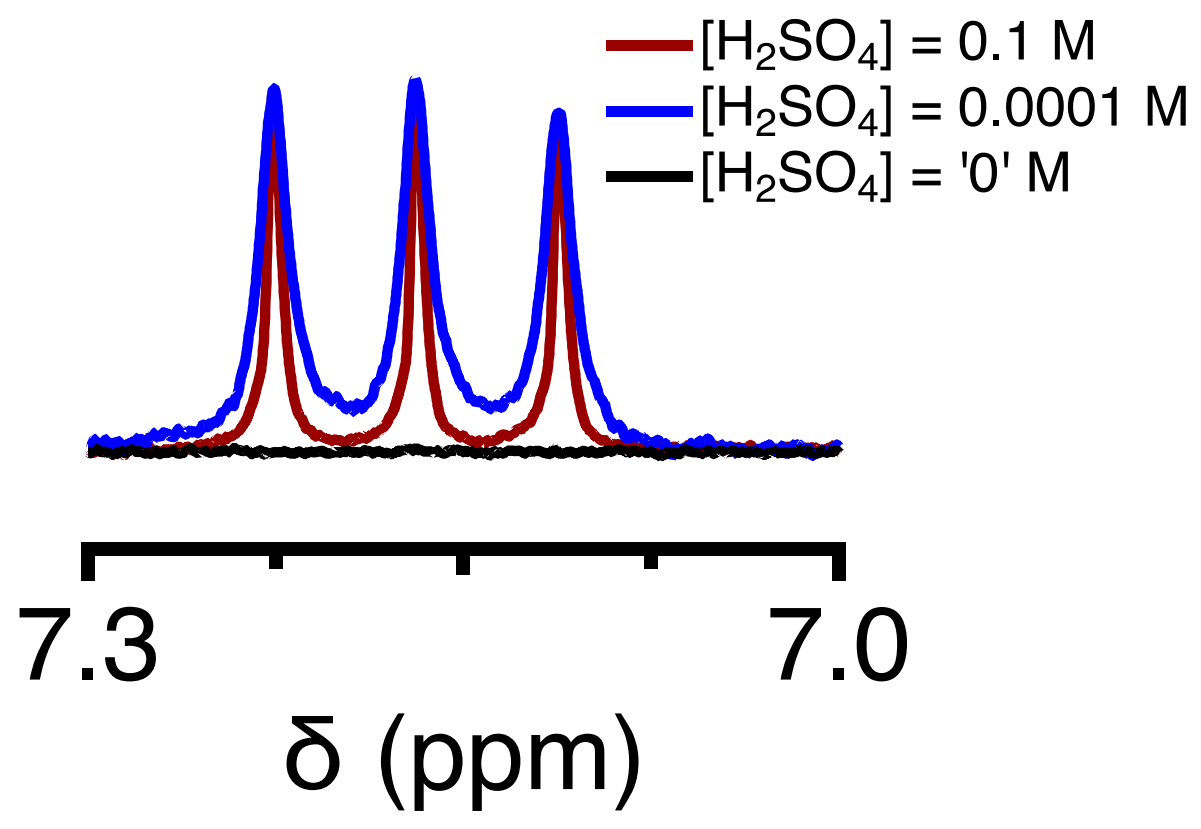

Figure S10. NMR spectra of $100 \mu \mathrm{M} \mathrm{NH}_{4}{ }^{+}$in EtOH at various $\mathrm{H}_{2} \mathrm{SO}_{4}$ concentrations. Linewidth at half max for $0.1 \mathrm{M} \mathrm{H}_{2} \mathrm{SO}_{4}=5.9 \mathrm{~Hz}$. Linewidth at half $\max$ for $0.0001 \mathrm{M} \mathrm{H}_{2} \mathrm{SO}_{4}=13.0 \mathrm{~Hz}$. No $\mathrm{NH}_{4}{ }^{+}$ resonance was observed when no $\mathrm{H}_{2} \mathrm{SO}_{4}$ was added. 


\section{2) $\mathrm{NH}_{4}{ }^{+}$resonance peak shape dependence on locking solvent}

(A)

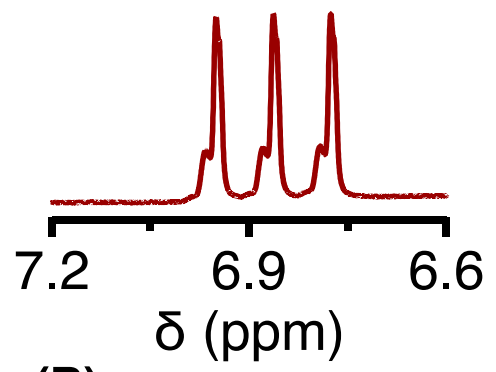

(B)

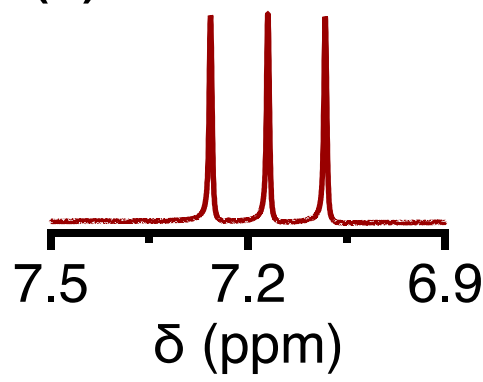

Figure S11. NMR spectra of $10 \mathrm{mM} \mathrm{NH}_{4}{ }^{+}$in EtOH using (A) $0.5 \mathrm{M} \mathrm{D}_{2} \mathrm{O}$ as a deuterated locking solvent and (B) $0.5 \mathrm{M} \mathrm{CD}_{3} \mathrm{CN}$ as a deuterated locking solvent. The smaller 1:1:1 triplet downfield of the larger triplet in $(A)$ was assigned to a $\mathrm{NH}_{3} \mathrm{D}^{+}$isotopologue formed via $\mathrm{H} / \mathrm{D}$ exchange. The broadening of the ammonium resonance in the presence of exchangeable deuterium sources demonstrated the value of selecting locking solvents that did not have exchangeable deuterium. Spectra were taken on $600 \mathrm{MHz}$ Varian INOVA equipped with a room temperature probe. We also note here that the use of a cryoprobe may be advantageous in promoting use of various deuterated locking solvents as the concentration of deuterium needed to generate adequate signal locking is reduced. 


\section{3) Colorimetric (Berthelot) $\mathrm{NH}_{3}$ detection characterization}

The extinction coefficient, reaction rate, color stability, salt dependence, and illumination dependence of the salicylate-based ammonia detection reaction were studied in four common electrochemical solvents (See 'Colorimetric Methods' section of the SI for experimental details). Table S1 displays the reactant conditions applied in each solvent (THF, propylene carbonate, ethanol, and water) as well as comparisons of the analyte responses under various reaction conditions. 
Table S1: Reaction conditions and results for the salicylate-based ammonia detection method executed in THF, propylene carbonate, ethanol, and water-based electrolytes. Each electrolyte solution contained $100 \mu \mathrm{M} \mathrm{NH}_{3}$ and 0.1M LiOTf prior to dilution and were developed under lab illumination conditions except where noted.

a Electrolytes were diluted percent by volume with $\mathrm{H}_{2} \mathrm{O}$ or $\mathrm{EtOH}$ to promote rapid, reproducible, homogeneous reaction solutions. Each analyte solution was also diluted with a small amount of water as a result of using aqueous reactant solutions. ${ }^{b}$ Reaction time is defined as the time point at which the maximum salicylate-based ( $\left.\lambda_{\max }=660-670 \mathrm{~nm}\right)$ absorbance was observed $\left(A_{\max }\right)$. Measurements were taken at $15 \mathrm{~min}, 30 \mathrm{~min}, 45 \mathrm{~min}, 60 \mathrm{~min}, 90 \mathrm{~min}, 2 \mathrm{hr}, 4 \mathrm{hr}, 8 \mathrm{hr}, 12 \mathrm{hr}$, and $24 \mathrm{hr}$. ${ }^{c}$ Color stability was defined as the length of time after the observation of $A_{\max }$ that the measured absorbance was within $5 \%$ of that maximum value.

d Extinction coefficient is reported at the $\lambda_{\max }$ for solutions containing $0.1 \mathrm{M}$ LiOTf and stored under laboratory illumination conditions.

e Light sensitivity is defined as the percent difference in $A_{\max }$ between an analyte stored under ambient laboratory illumination conditions and one stored in the dark. Values are defined with respect to the illuminated analyte (e.g $-10 \%$ suggests a $10 \%$ decrease in the dark sample $A_{\max }$ with respect to the illuminated sample.

${ }^{f}$ Supporting electrolyte sensitivity is defined as the percent difference in $\mathrm{A}_{\max }$ between an analyte composed of $100 \mu \mathrm{M} \mathrm{NH}$. and 0.1M LiOTf against one composed of $100 \mu \mathrm{M} \mathrm{NH}$. No color development was observed for the propylene carbonate electrolyte when no supporting electrolyte was present. Values are defined with respect to the analyte containing 0.1M LiOTf.

THF Propylene Ethanol $\quad \mathrm{H}_{2} \mathrm{O}$ Carbonate

\begin{tabular}{|c|c|c|c|c|}
\hline Sodium Salicylate & $0.25 \mathrm{M}$ & $0.25 \mathrm{M}$ & $0.25 \mathrm{M}$ & $0.25 \mathrm{M}$ \\
\hline $\mathrm{NaOCl}$ & $0.02 \mathrm{mM}$ & $0.02 \mathrm{M}$ & $0.02 \mathrm{M}$ & $0.02 \mathrm{M}$ \\
\hline $\mathrm{NaOH}$ & None & None & $0.01 \mathrm{M}$ & $0.01 \mathrm{M}$ \\
\hline $\mathrm{Fe}(\mathrm{CN})_{5}(\mathrm{NO})^{-}$ & $8 \times 10^{-4} \mathrm{M}$ & $8 \times 10^{-4} \mathrm{M}$ & $4 \times 10^{-3} \mathrm{M}$ & $4 \times 10^{-3} \mathrm{M}$ \\
\hline Solvent conditions ${ }^{a}$ & $\begin{array}{l}50 \% \\
\text { electrolyte } \\
50 \% \mathrm{H}_{2} \mathrm{O}\end{array}$ & $\begin{array}{l}50 \% \text { electrolyte } \\
25 \% \mathrm{H}_{2} \mathrm{O} \\
25 \% \mathrm{EtOH}\end{array}$ & $\begin{array}{l}50 \% \text { electrolyte } \\
50 \% \mathrm{H}_{2} \mathrm{O}\end{array}$ & $100 \%$ electrolyte \\
\hline Reaction time $^{b}$ & $2 \mathrm{hr}$ & $4 \mathrm{hr}$ & $90 \min$ & $30 \mathrm{~min}$ \\
\hline Color Stability ${ }^{c}$ & $>12 \mathrm{hr}$ & $>12 \mathrm{hr}$ & $>12 \mathrm{hr}$ & $>12 \mathrm{hr}$ \\
\hline $\begin{array}{l}\text { Extinction coefficient }{ }^{d} \\
\left(\mathrm{M}^{-1} \mathrm{~cm}^{-1}\right)\end{array}$ & $4.4 \times 10^{3}$ & $3.4 \times 10^{3}$ & $1.47 \times 10^{4}$ & $1.45 \times 10^{4}$ \\
\hline Light sensitivity & Minimal & $\sim 40 \%$ & Minimal & Minimal \\
\hline $\begin{array}{l}\text { Supporting }{ }^{f} \\
\text { electrolyte sensitivity }\end{array}$ & $\sim-50 \%$ & Critical & $<-10 \%$ & Minimal \\
\hline
\end{tabular}


Sodium salicylate was chosen over phenol as the phenolic precursor for the reaction after the observation of a penetrating odor when using phenol as the reactant in non-aqueous solvents. This is consistent with previous literature reports that suggest that orthochlorophenol can form during the reaction with phenol. ${ }^{7}$ The conditions needed to observe ammonia colorimetrically (indirectly as dicarboxylated indophenol) were similar but not identical between solvents, particularly with respect to the necessity of hydroxide addition, which was not useful in either THF or propylene carbonate. The color stability and illumination sensitivity varied between electrolyte and reaction conditions and the reaction time varied substantially between electrolytes. The salt sensitivity also varied, but did not preclude the use of electrolytes. It is interesting to note that the presence of supporting electrolyte was necessary to observe the development of color in propylene carbonate. The large extinction coefficient $\left(>500 \mathrm{M}^{-1} \mathrm{~cm}^{-1}\right.$ ) in each electrolyte is indicative of the high sensitivity of this method (See Figure S12 and S13).

The key conclusion is that ammonia is directly detectable in any of the four electrolytes using the Berthelot method, but that careful control of the reaction conditions must be executed if using as an analytical technique in non-aqueous electrolytes. Effectively all of the analytical parameters varied with changes in the reaction conditions, and thus calibration curves that reflect the exact electrochemical conditions under which the ammonia will be detected must be developed prior to using this method. 
(A)
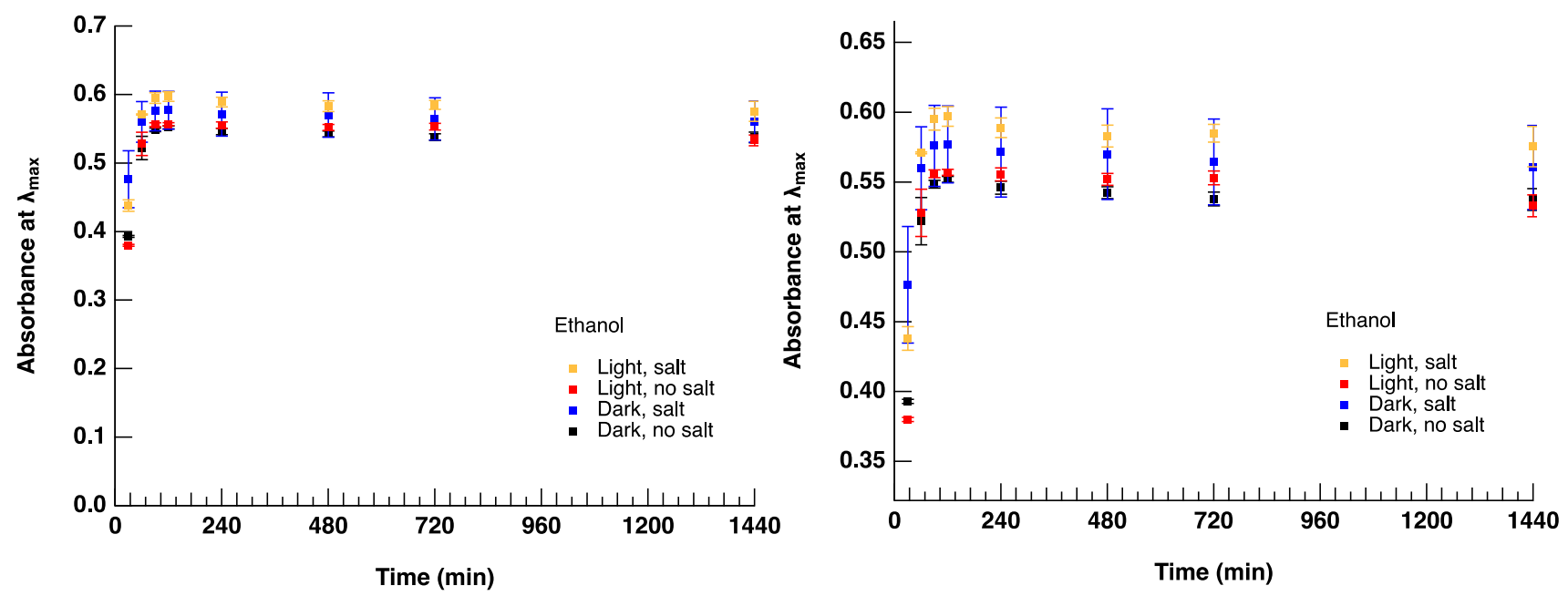

(B)

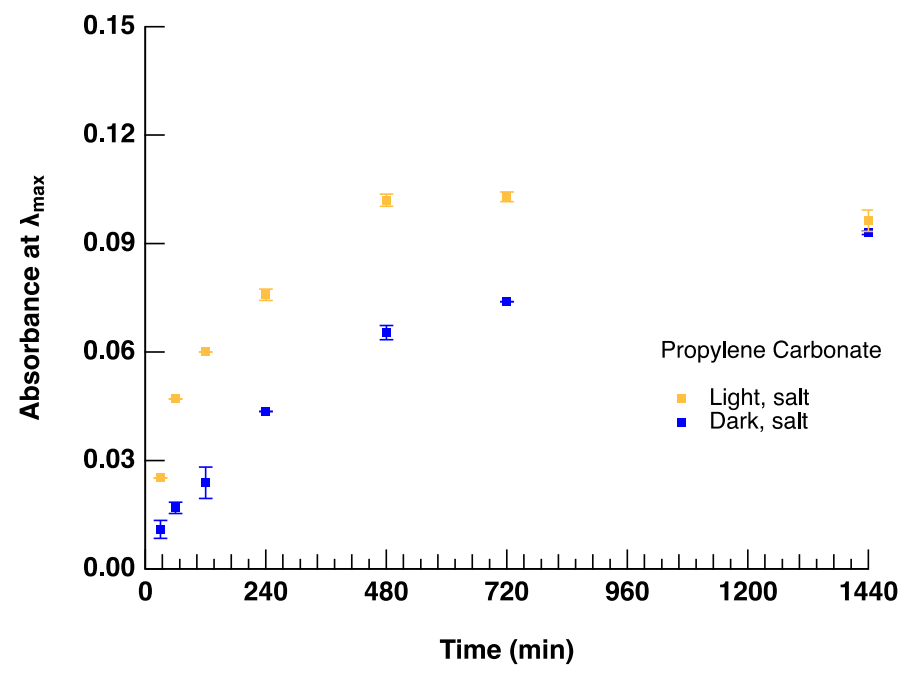


(C)

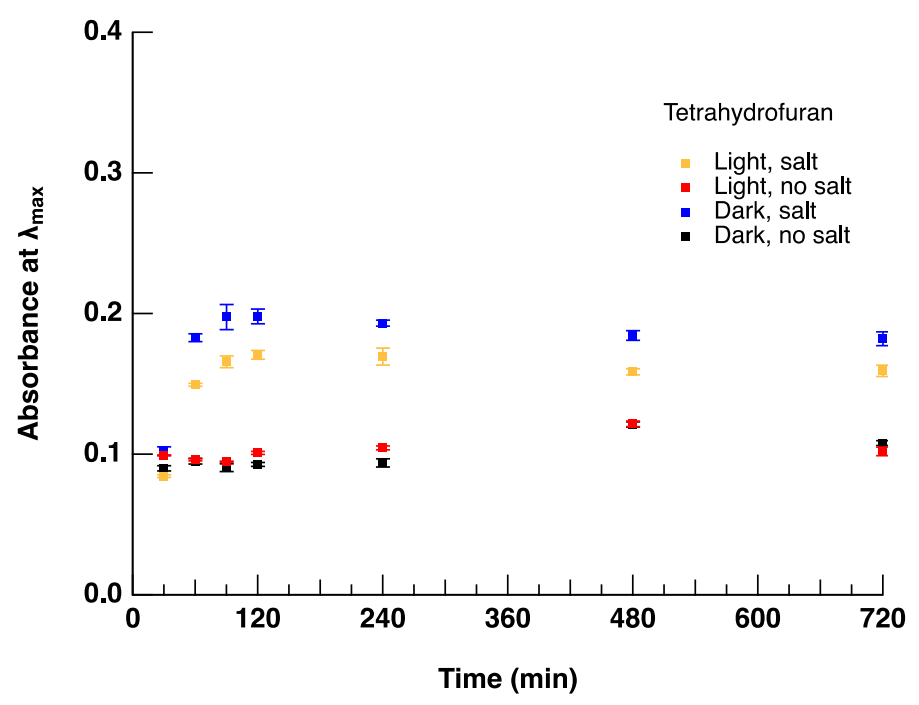

(D)
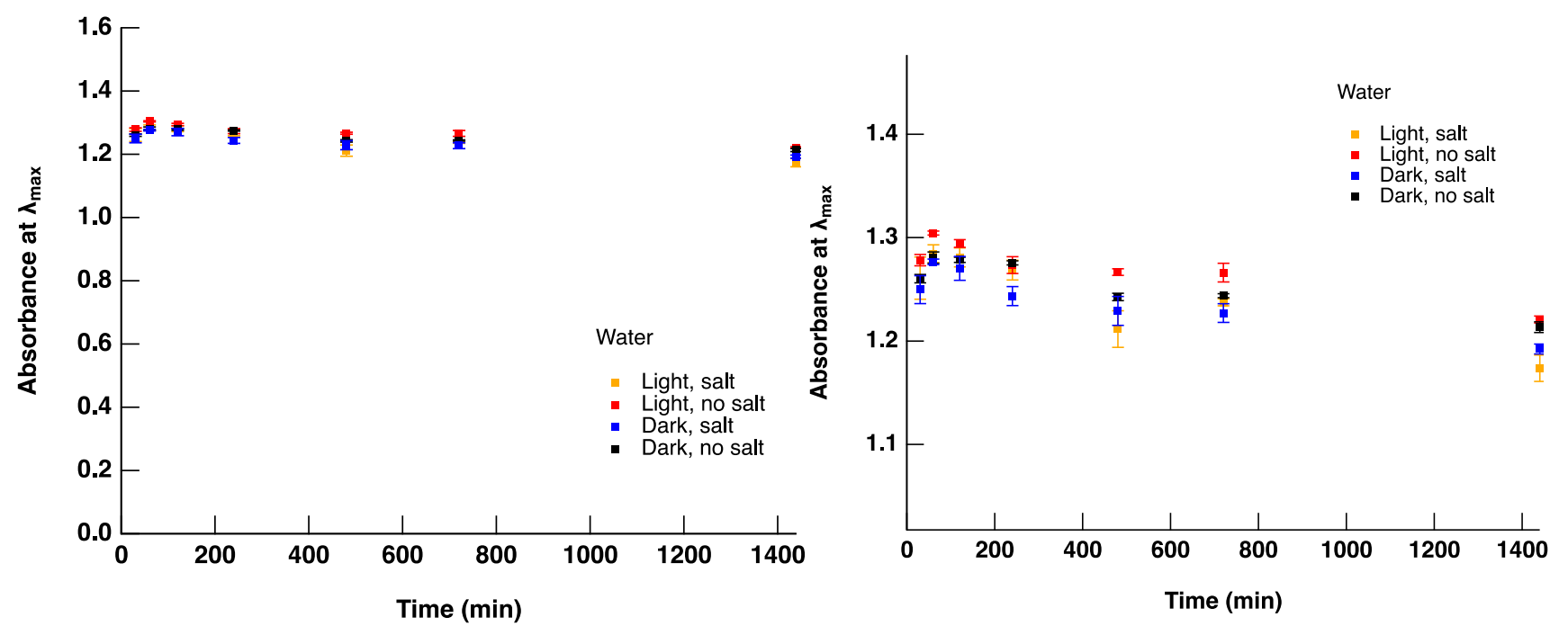

Figure S12. Absorbance at $\lambda_{\max }(660-670 \mathrm{~nm})$ with respect to total reaction time for $100 \mu \mathrm{M}$ $\mathrm{NH}_{3}$ dissolved in various electrolytes and under various reaction conditions. Reaction conditions were varied with respect to the presence or absence of $0.1 \mathrm{M} \mathrm{LiOTf}$ in the analyte (salt/no salt) and with respect to analyte development under laboratory illumination or under dark conditions (light/dark). Data is reported for electrolytes/solutions in A) ethanol, B) propylene carbonate, C) THF, and D) water. Panels on the right are zoomed in versions of the panels on the left. Error bars represent the total standard deviation about the mean absorbance value. $\lambda_{\max }$ was observed to blue-shift slightly with addition of $0.1 \mathrm{M}$ LiOTf when compared to salt-free solutions. 
(A)

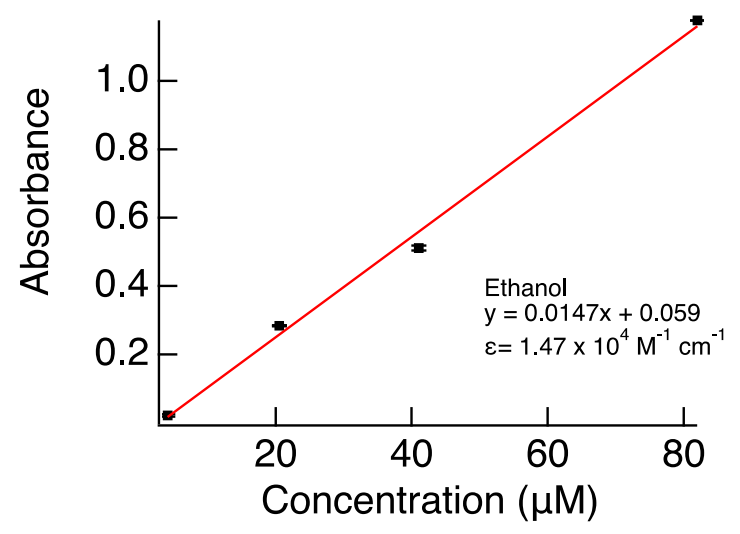

(C)

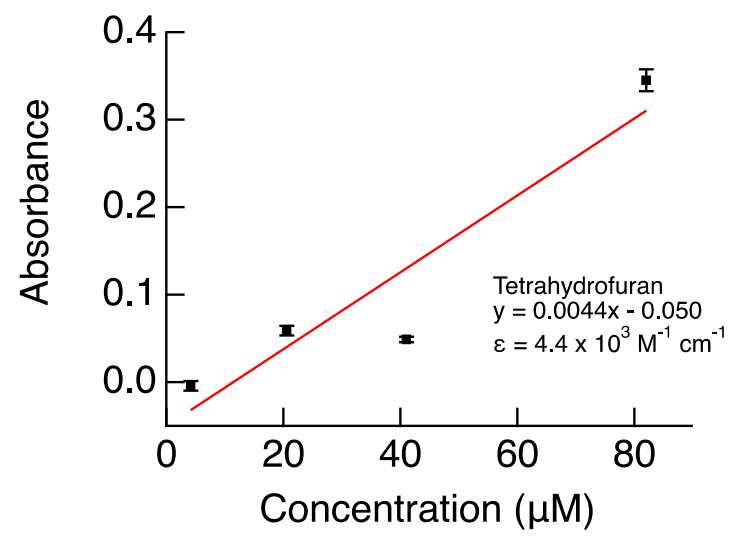

(B)

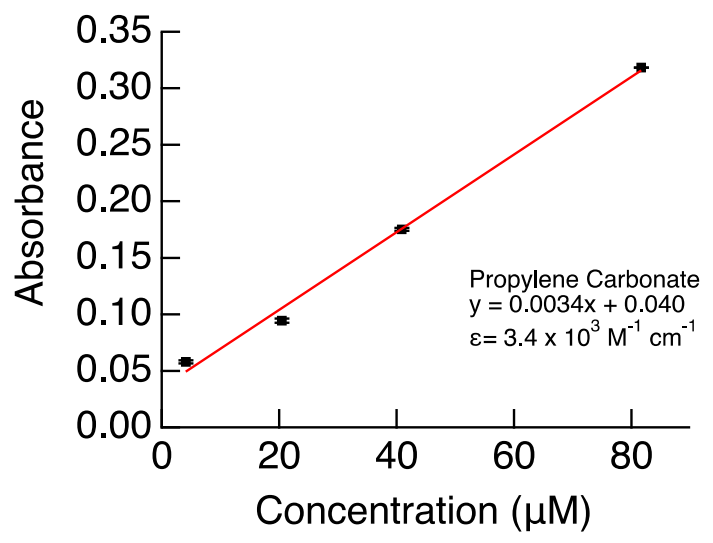

(D)

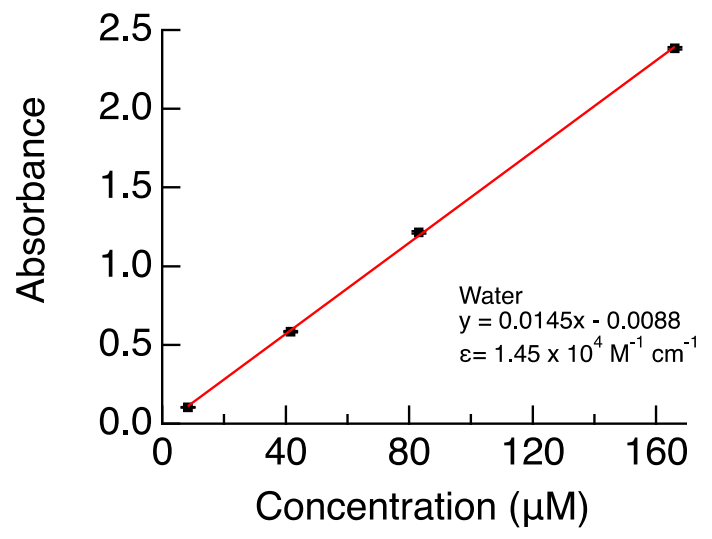

Figure S13. Calibration curves for the colorimetric detection (Berthelot method) of $\mathrm{NH}_{3}$ in a 0.1 M LiOTf electrolytic solution developed under laboratory illumination in a) ethanol, b) propylene carbonate, c) THF, and d) water. Derived extinction coefficients are reported in Table S1 and can be seen. Absorbance values used herein were corrected with respect to a background spectrum composed of identical electrolyte and reaction conditions, but no measurable $\mathrm{NH}_{3}$. 


\section{SI References}

(1) Guéron, M.; Plateau, P.; Decorps, M. Solvent Signal Suppression. Prog. NMR Spectrosc. 1991, 23, 135-209.

(2) Barantin, L.; Pape, A. Le; Akoka, S. A New Method for Absolute Quantitation of MRS Metabolites. Magn. Reson. Med. 1998, 38, 179-182.

(3) Akoka, S.; Barantin, L.; Trierweiler, M. Concentration Measurement by Proton NMR Using the ERETIC Method. Anal. Chem. 1999, 71, 2554-2557.

(4) Wider, G.; Dreier, L. Measuring Protein Concentrations by NMR Spectroscopy. J. Am. Chem. Soc. 2006, 128, 2571-2576.

(5) Tsuneto, A.; Kudo, A.; Sakata, T. Efficient Electrochemical Reduction of N2 to NH3 Catalyzed by Lithium. Chem. Lett. 1993, 851-854.

(6) Andersen, S. Z.; Colic, V.; Yang, S.; Schwalbe, J. A.; Nielander, A. C.; McEnaney, J. M.; Enemark-Rasmussen, K.; Baker, J. G.; Singh, A. R.; Rohr, B. A.; Statt, M. J.; Blair, S. J.; Mezzavilla, S.; Kibsgaard, J.; Vesborg, P. C. K.; Cargnello, M.; Bent, S. F.; Jaramillo, T. F.; Stephens, I. E. L.; Norskov, J. K.; Chorkendorff, I. A rigorous electrochemical ammonia synthesis protocol with quantitative isotope measurements. Nature 2019. DOI: $10.1038 / \mathrm{s} 41586-019-1260-\mathrm{x}$

(7) Verdouw, H.; Van Echteld, C. J. A.; Dekkers, E. M. J. Ammonia Determination Based on Indophenol Formation with Sodium Salicylate. Water Res. 1978, 12, 399-402. 